\title{
Multi-thermal performance optimization of semi-circular heat pipes integrated with various solar collector profiles
}

\author{
Mohammed Yunus ${ }^{*}$ (D) and Mohammad S. Alsoufi
}

\begin{abstract}
Solar collector (SC) technology has proved promising applications in heating, desalination, refrigeration of water, etc. Thermal performance (TP) of Heat Pipe (HP) improves by combining the various profiled absorber plate with a flat-plate collector. The objective is to study HP attributes' effect (heat inputs, pipe inclinations, and mass flow rates of water) with various profiles of absorber plates in a flat-plate SC on the TP. Semi-circular HP combining with the flat, V-grooved, and V-troughed absorber plates in a flat-plate collector improved TP. They are heat output, thermal resistance, and overall efficiency explored experimentally by adapting the response surface method's (RSM) central composite design. A major impacting applicant factor was heat input for improving TPs, and correlation models were generated from ANOVA. The optimal input attributes are obtained to minimize thermal resistance and maximize heat output and overall efficiency from RSM and desirability function. Confirmation test was conducted using optimal settings and their corresponding estimated values of the TP attributes to compare with the experimental results shown very close agreement between them established.
\end{abstract}

Keywords: Response surface methodology, Central composite design, Solar collector, Renewable energy resources, Thermal performances

\section{Introduction}

The amount of renewable energy required for day-to-day activities is increasing, leading to a rise in global warming, carbon emissions, technological innovations, and the scarcity of fossil fuels due to rapid urbanization and industrialization worldwide. In a quest for clean and renewable energy technology, solar collectors have been successfully used in the heating, refrigeration, desalination of water, heat pumps, etc. Solar energy (SE) is in the form of radiation released by reactions due to nuclear fusion. Only $1 / 3$ of SE touches our planet, and in every $1 / 3 \mathrm{~h}$, the sun harvests a high adequate amount of energy to feed its annual demands (Faghri 1995). The most straightforward route of grabbing SE is by converting it

\footnotetext{
*Correspondence: myhasan@uqu.edu.sa; yunus.mohammed@rediffmail.com Department of Mechanical Engineering, College of Engineering and Islamic Architecture, Umm Al-Qura University, Makkah, KSA, Saudi Arabia
}

into beneficial thermal energy directly. Various kinds of devices are available for this conversion. Among SE collectors, special types of heat exchangers convert radiation into the transportation medium's internal energy such as air, water, or oil. Non-tracking or stationary and tracking collectors are used. A stationary collector has a fixed amount of catching area for absorbing solar radiation energy irrespective of sun location in the sky. It is classified as the flat-plate, evacuated tube, and compounded parabolic collectors. They are mounted at various orientations depending on the geographic position (latitude) to amplify solar radiation. Flat-plate collectors have been successfully used in multiple applications for an extended period without any necessary modifications in design and operation (Riffat et al. 2005). Water pipes are joined to the collector plate in which water flows with or without an external pump to transfer the heat to a storage tank. Heat pipe (HP)s are the solution to overcome the drawbacks such as the ample space required for the free 
distribution system, corrosion effect of water, pump and power costs for operating them, and the substantial temperature drop (Riffat and Zhao 2004).

HP solar collectors (HPSC) consisting of a sealed tube carrying water were employed to overcome these drawbacks. By working fluid evaporation, the heat transfers to a condensing region, such that the vapor gets condensed to return to the vaporizing region via a capillary zone. Several attempts have been made to study geometry as well as the efficiency of HPs as they are made of a group of individually sealed pipes having a condenser zone. HP efficiency depends on the geometry (the area of condenser sectional surface) using a theoretical and experimental study of the wickless HP solar collectors used in water heating using a heat exchanger of the cross-flow condenser type (CFCHE) (Hussein 2003). Higher efficiency was determined at an optimum cooling distilled water flow rate. Meanwhile, computational fluid dynamics (CFD) methods evaluated the effectiveness of HPSC in terms of the results of heat transfer of the condenser (CFCHE type) used for mixing natural and forced convective CFD models on par with experimental results (Facão and Oliveira 2006). The effect of the various cross section of HP (circular, elliptical, and semi-circular) and water at different filling ratios $(10 \%, 20 \%$, and $35 \%)$ was conducted experimentally by a fixed flow rate with declined input temperature of cooling water and at quasisteady-state condition during the morning and the afternoon, respectively (Hussein et al. 2006).

A novel HPSC performance using thermal efficiency at various temperatures was determined on an outdoor test facility, and the mathematical model was developed using an effectiveness-NTU method (Azad 2008). The efficiencies of three types of parallel HPSC were evaluated for finned HP (Type I), solar collector (Type II), and four tube heat exchanger (Type III) under identical conditions and compared. Results showed that the efficiencies of Type I were less than Type II and III (Azad 2012). A novel HPSC design connecting all pipes of top and base tubes using ethanol working fluid with a mass flow rate of $0.2 \mathrm{~kg} / \mathrm{s}$, which developed the highest efficiency (66\%), was proposed (Wei et al. 2013). Aluminium-sealed HPSC with in-built fin without welds as a single part using a sheet metal extrusion method studied for efficiency at various tilt angles $\left(0^{\circ}\right.$ to $\left.90^{\circ}\right)$ showed conformity with those of commercial HPSC, which demonstrated high efficiency (Saravanan and Karunakaran 2014). Experimental studies were performed on the V-type absorber plate in HPSC to increase higher absorption per unit area over the conventional solar collectors.

RSM was used to optimize the shape of a single-phase parallel-flow heat exchanger for heat and flow characteristics obtained by numerical analysis (Chun et al. 1999).
A central composite design with a full replication technique of RSM was used to optimize five levels of three process parameters for thermal performance of water to air thermo-syphons HP heat exchanger (Senthilkumar et al. 2014). A 3-D CFD simulation for evaluating total heat transmission and efficiency in the cooling mode using the second-order RSM to develop the regression model at optimum conditions was developed (Khalajzadeh et al. 2011). RSM was employed to optimize a proposed heat exchanger tube shape to decrease its size for increasing thermal performance was obtained from finite element analysis. A regression model was developed between thermal performance and the geometric parameters of a tube (Hull 1986).

RSM was found useful in two-level interactions of design parameters of an elliptical flat type heat exchanger numerical model for maximizing fluid flow and heat transfer on both sides of air and water circulation (Zhang et al. 2014). The optimization of the parameters such as diameter, heat input, tilt angle, filling ratio, and flow rate in the condenser for the thermal efficiency of an HP was carried out using CCD of RSM with the aid of the design of expert software (Ramakrishnan and Arumugam 2011).

RSM was utilized to optimize a collector's efficiency while checking Nanofluid's transient equilibrium and finding the effective parameters like filling ratio and mounting tilt position along with correlation and interactions between them (Sarafraz et al. 2019). Magnetically excited HP employing various ferrofluids has shown increasing the input heat fluctuation, enriching transmit coefficient (h) of the PHP in case of $\gamma-\mathrm{Fe}_{2} \mathrm{O}_{3}$ (Goshayeshi et al. 2016). Then work was extended to inclined HP magnetically excited also shown improved $h$ and thus found HP orientation affected the TP (Goshayeshi et al. 2016). Trials using graphene-methanol and NPE as a surfactant evaluated the effectiveness of an SC of HP shown an improved efficiency along with thermal conductivity of methanol Olia et al. (2019). Trials to assess the TP of tube-type SC using nano-fluid consisting of carbon nanoparticles (NP) spreaded in acetone by considering the percent of volume, percent of the mass of the NP, orientation, etc., as input elements were conducted. Increasing flow rate improved the efficiency, and the best orientation was at $30^{\circ}$ angle as well as $60 \%$ was the best filling ratio improved the SC efficiency to $91 \%$ Sarafraz and Safaei (2019). Experimental work on magnetically excited copper $\mathrm{HP}$ carrying $\mathrm{Fe}_{2} \mathrm{O}_{3} /$ Kerosene nano-fluid provided heat distribution and transfer rate in the absence of a magnetic field. $\mathrm{Fe}_{2} \mathrm{O}_{3} \mathrm{NP}$ enhanced TP and $\mathrm{h}$ in magnetically excited HP (Sarafraz et al. 1877). Recent updates in the nano-fluids applications on parabolic-troughed collectors (PTC) impact several elements like percentage of volume and size of NP on PTC performance. 
Experimentation and CFD-related work were reviewed to assess the input elements impact on h, efficiency, entropy, and pressure variation in PTC. Nano-fluids improved efficiency and ' $h$ ' but reduced the entropy and the pressure (Hooman et al. 2019).

A thorough literature review revealed that limited studies had been completed in the field of flat-plate solar collector/simulator HPs. Research on nano-fluids with NP for PTC was limited to the circular HP. Different investigations show that various variables affecting the thermal performance, especially the semicircular geometry of the HP and absorber plate profiles (V-grooved, flat, and V-troughed), are not discussed. Various cross-sections of HP on different solar collector's profiles with multi-leveled input variables (like Heat Input, Inclination, and Mass Flow Rate) and multiple performance characteristics pose challenges to assess the conditions involving costliest experiments. Many researchers are focusing on forecasting of results of various HP by demonstrating tools rather than fullfledged experiments. ANN, ANNFIS, can determine non-linearity relations in the data provided but demand huge trial data. Whereas RSM is adequate to achieve the logical values with minimum experimentation data and easy to implement, and results will be very close to other techniques when available data are low. A correlational model to forecast the results without experimentation at an optimum level of their inputs to maximize or minimize the TP's attributes can be generated. Therefore, in the present study, multi-response optimization using a CCD matrix of RSM method was used for improving the TP under various input factors (Yunus and Alsoufi 2016a, 2018).

\section{Materials and methods}

In the current research, the experimentations are designed and performed using a three-level, three-factor CCD type of RSM.

\section{Response surface methodology (RSM) and central composite design (CCD)}

Any process needs to have the optimum values of input variables for optimizing (either maximizing or minimizing) the output characteristics in terms of inputs. Response surface methodology (RSM) utilizes accumulated available useful statistical and mathematical methods to model and analyze engineering processes' problems, such that response surface influenced by various input factors becomes optimized. RSM can quantify the quality level and establish the correlation between the input variables and the concerned output surfaces (Yunus and Alsoufi 2016b). The step-by-step procedure of RSM is depicted inFig. 1. Validation of the optimized

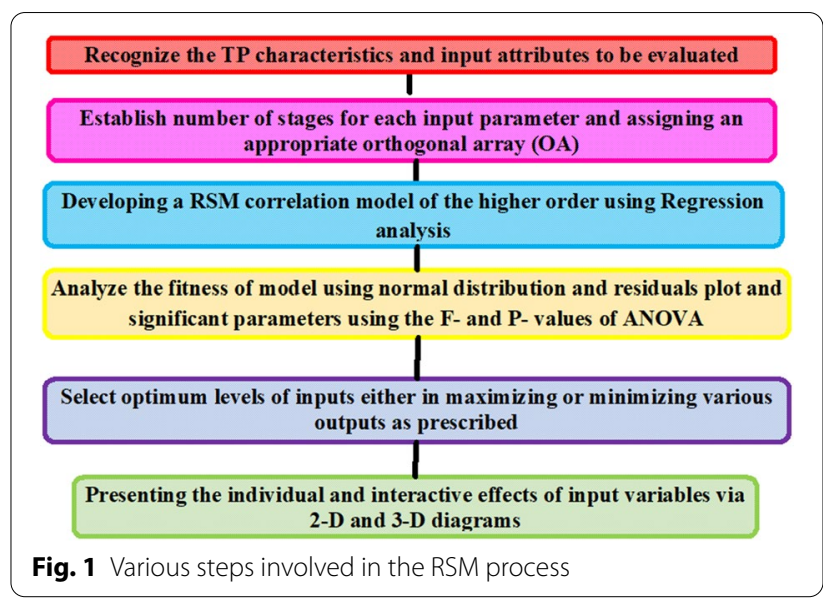

Table 1 Process parameters and their levels

\begin{tabular}{lcrr}
\hline Parameters & Levels & & \\
\hline Heat input $(A)$ & 700 & 1100 & 1500 \\
Inclination angle $(B)$ & 30 & 45 & 60 \\
Mass flow rate $(C)$ & 90 & 115 & 135 \\
\hline
\end{tabular}

conditions is ensured by conducting verification experiments. Ultimately, the optimized profile absorber plate and best input conditions of HP in a flat-plate solar simulator were identified.

RSM design allows informed estimation of the interaction of variables at different levels and even their quadratic effects through the surface responses' shape under examination. Box-Behnken and Central Composite are the two practical designing methods for fitting the second-order polynomials to response surfaces. They needed a few interpretations to evaluate the factors formed by both the higher and lower limits for each variable, as shown in Table 1.

\section{Experimental conditions proposed by CCD}

The experimentation scheme was carried out under the following titles: semi-circular HP with flat, V-grooved, V-trough absorber plates. Experiments are conducted by varying the heat input of $1100 \mathrm{~W}$ to $2000 \mathrm{~W}$, angle of inclination from $30^{\circ}$ to $60^{\circ}$, and the flow rate from $120 \mathrm{ml} / \mathrm{min}$ to $150 \mathrm{ml} / \mathrm{min}$. The wall temperatures of (vaporizing and condensing regions) an HP are recorded for the above attributes. The variables mass flow rate $(C)$, pipe orientation $(B)$, and heat input $(A)$ are elected as independent attributes in designing the experiments. Twenty-seven trials are conducted to assess the influences of input attributes on the thermal resistance (TR), heat output (HO), and thermal efficiency (TE). Input 
attributes are reflected as dependent TP results on the range and levels of independent process variables for a flat-plate solar simulator system. The experimental conditions proposed by RSM for FPSS in coded values are tabulated in Table 2. In this research work, central composite design involving three factors at three levels is a learned method for designing the experiments covering various conditions. The experimentation scheme was carried out under the following instances of semi-circular HP with flat, V-grooved, and V-trough absorber plate, as shown in Tables 3, 4, 5 .

\section{Experimental results}

An experimental setup was made to accommodate flat, $\mathrm{V}$-grooved, and then $\mathrm{V}$-trough solar collector absorption plates using a semi-circular HP. The solar collector absorber plates for the HP were made to store and circulate heat produced as the heat is transferred into a fluid by evaporation and condensation. The $\Phi 18 \times 1200$ length pipe has an $840 \mathrm{~mm}$ evaporator, $120 \mathrm{~mm}$ adiabatic, and $240 \mathrm{~mm}$ condenser length made of copper. The wick has two layers of $50 \mathrm{in}^{2}$ mesh formed by a stainlesssteel screen of $12 \times 24$ and thickness of $1.2 \mathrm{~mm}$ connected to the evaporator region, set in a flat, V-grooved, and V-trough absorber plates. The HP, solar collector absorber plates (flat, V-grooved, and V-trough), and water stored tank are required to perform experiments. Distilled and deionized water is used as a working fluid in the HP. There is insulation made of glass wool underneath the absorber plates. The sides are covered by thermocol and glass plates to reduce the conduction, convective, and radiation losses. The solar intensity $\left(\mathrm{W} / \mathrm{m}^{2}\right)$ is gauged using a solar power tester. The thermocouples ( $K$-type) assessed the wall temperature of HP, and other elements like absorber and the glass plate were indicated in the temperature dial at an error level of $\pm 0.1^{\circ} \mathrm{C}$. A rotameter controls the condenser region's flow to maintain the 120 , 135 , and $150 \mathrm{ml} / \mathrm{min}$.

Three absorber plate profiles are used in the plate SC, and the vaporizing region of the HP is covered with black paint to capture a large quantity of the incident sun radiations. Heat exchangers of plate SC are formed using three industrial copper tubes of $24 \mathrm{~mm} \times 0.18 \mathrm{~m}$ (outside diameter $\mathrm{x}$ length) and brazed to two concentric end caps at every tube is connected by brazing. Also, heat exchangers are joined with two copper tubes of $6 \mathrm{~mm}$ for supplying water at the inlet and outlet. Each HP assembly is in-built into a protected covering (collector).

The above procedure is repeated for every power input keeping the flow rate at the condenser section and inclination constant throughout the experiments.
Experiments were conducted for the HP integrated with various profiles of absorber plate with different input elements, such as heat input $(A)$, mass flow rate $(B)$, and inclinations $(C)$.

The semi-circular HP is integrated with three absorber plates in a solar simulator and analyzed by RSM using CCD design. Using the CCD method, the input components and the output results of optimization resulted in 27 runs adopted using Taguchi design of experiments to achieve a second-order polynomial, which is used to study the performance of a semi-circular HP (refer Table 2).

\section{Results and discussion}

The prime goal of the current work is to assess the effect of various governable input elements on Heat output (HO), thermal resistance (TR), and overall thermal efficiency (TE) as output elements.

\section{Results of ANOVA for HO, TR, and TE}

The output characteristics of three absorber plates are given in the form of ANOVA (Tables 3, 4, and 5), showing the model $F$ value more than four imply that the model is significant in the three types of absorber plates. Adopting only a $1 / 100 \%$ probability that a "model F-value" is large might arise because of noise. The lowest probability value demonstrates the significance of the model terms and is eventually selected for indicating the value of the coefficients to allow the instances of interactions between the elements of solar collector and the outputs with its least value, the correlation coefficient $\left(R^{2}\right)$ will be more. In the present RSM analysis, the model fitting extraction endorses a statistically meaningful model is the second order or (quadratic) type for the outputs HO, TR, and TE using ANOVA results. The $R^{2}=1$ represents the TP fits the original quantities and is well predicted and adjusted $R^{2}$ advancing to 1 , and the model is considered more accurate. Adequacy check is ensuing to high-level value guarantees suitable agreement of assessed quantities at the optimal set with an average prediction error. $R^{2}$-standard, $R^{2}$-predicted, and $R^{2}$-adjusted for $\mathrm{HO}, \mathrm{TR}$, and TE, signifying that the regressive model provides good relations between keyed elements and TP. The top controllable factors were chosen with the smaller $p$ value. Figures $3 b, 4 b, 5 b$ show the distribution of data above and below the line indicates model fitting and adequacy check. The regression models are used to predict each response of the semi-circular pipe using the various shaped solar simulator as a function of process factors. The quadratic relation for the coded levels of the parameters is presented in Eqs. 1-9, respectively, for three responses. 


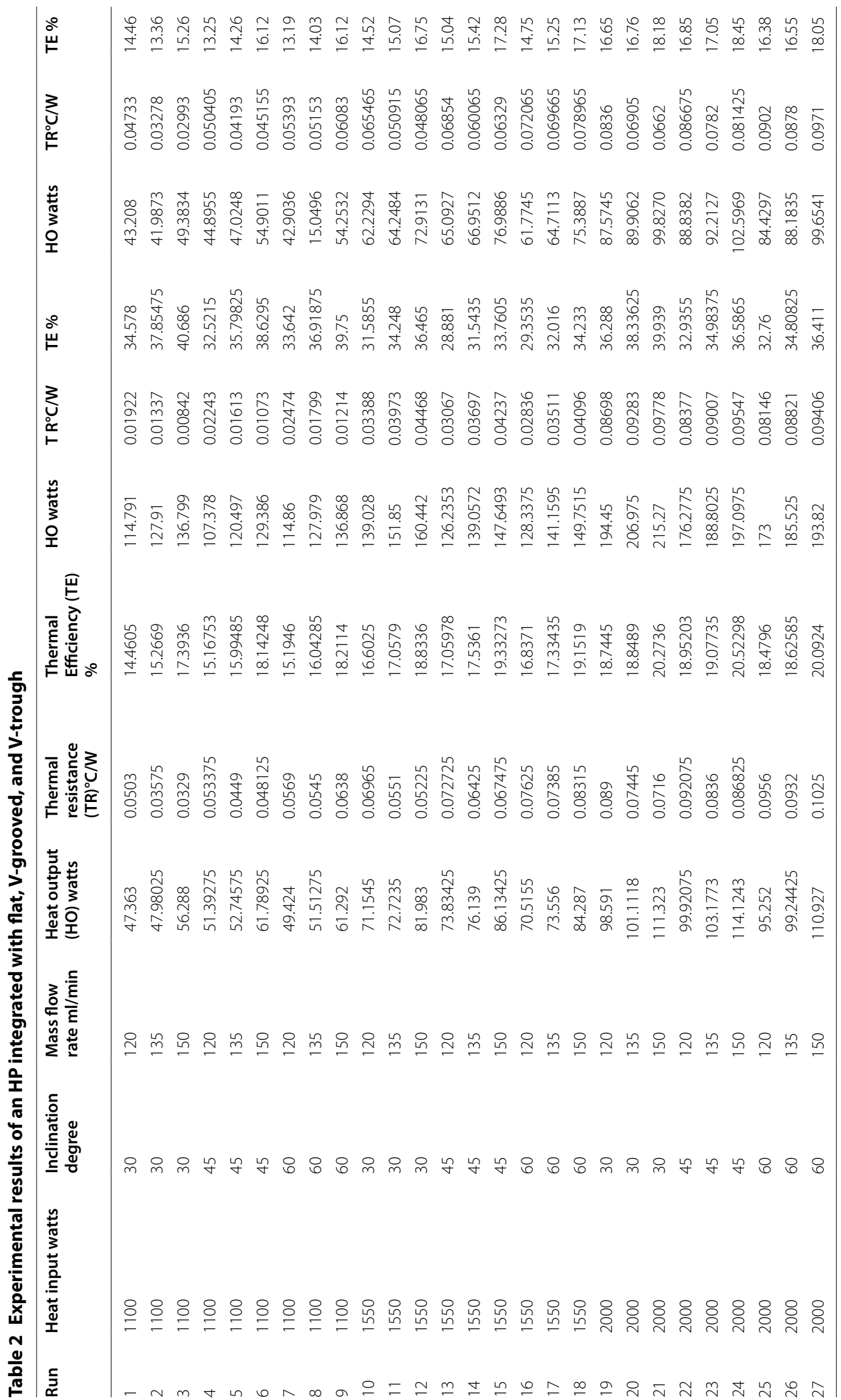


Table 3 ANOVA results of output characteristics of a flat absorber plate

\begin{tabular}{|c|c|c|c|c|c|c|c|c|c|c|c|c|c|}
\hline \multirow[t]{2}{*}{ Source } & \multirow[t]{2}{*}{ DF } & \multicolumn{4}{|c|}{ Heat output } & \multicolumn{4}{|c|}{ Thermal resistance } & \multicolumn{4}{|c|}{ Overall thermal efficiency } \\
\hline & & Adj SS & Adj MS & $F$ value & $p$ value & Adj SS & Adj MS & $F$ value & $p$ value & Adj SS & Adj MS & $F$ value & $P$ value \\
\hline Model & 6 & 12256.9 & 1751.0 & 450.17 & 0.000 & 0.009094 & 0.001299 & 81262.10 & 0.000 & 71.1974 & 10.1711 & 278.65 & 0.000 \\
\hline Linear & 3 & 12128.9 & 4043.0 & 1039.44 & 0.000 & 0.008446 & 0.002815 & 176096.22 & 0.000 & 66.3504 & 22.1168 & 605.93 & 0.000 \\
\hline$A$ & 1 & 11445.0 & 11445 & 2942.48 & 0.000 & 0.006740 & 0.006740 & 421572 & 0.000 & 42.7581 & 42.7581 & 1171.44 & 0.000 \\
\hline B & 1 & 3.1 & 3.1 & 0.80 & 0.382 & 0.001582 & 0.001582 & 98958.33 & 0.000 & 0.3439 & 0.3439 & 9.42 & 0.006 \\
\hline C & 1 & 680.8 & 680.8 & 175.03 & 0.000 & 0.000124 & 0.000124 & 7758.33 & 0.000 & 23.2484 & 23.2484 & 636.93 & 0.000 \\
\hline Square & & 88.7 & 88.7 & 22.81 & 0.000 & 0.000205 & 0.000205 & 12844.00 & 0.000 & 2.6148 & 2.6148 & 71.64 & 0.000 \\
\hline$C^{*} C$ & & 88.7 & 88.7 & 22.81 & 0.000 & 0.000205 & 0.000205 & 12844.00 & 0.000 & 2.6148 & 2.6148 & 71.64 & 0.000 \\
\hline 2-Way interaction & 3 & 39.2 & 13.1 & 3.36 & 0.040 & 0.000443 & 0.000148 & 9234.00 & 0.000 & 2.2322 & 0.7441 & 20.38 & 0.000 \\
\hline$A^{*} B$ & 1 & 21.9 & 21.9 & 5.62 & 0.028 & 0.000000 & 0.000000 & 0.00 & 1.000 & 0.7485 & 0.7485 & 20.51 & 0.000 \\
\hline$A^{*} C$ & 1 & 10.9 & 10.9 & 2.79 & 0.111 & 0.000000 & 0.000000 & 0.00 & 1.000 & 1.4784 & 1.4784 & 40.50 & 0.000 \\
\hline$B^{*} C$ & 1 & 6.5 & 6.5 & 1.67 & 0.212 & 0.000443 & 0.000443 & 27702.00 & 0.000 & 0.0053 & 0.0053 & 0.14 & 0.709 \\
\hline Error & 20 & 73.9 & 3.9 & & & 0.000000 & 0.000000 & & & 0.6935 & 0.0365 & & \\
\hline Total & 26 & 12330.8 & & & & 0.009094 & & & & 71.8909 & & & \\
\hline
\end{tabular}

$R^{2}=98.68 \%$

$R^{2}$ (adjusted) $=98.29 \%$

$R^{2}$ (predicted) $=97.91 \%$

Table 4 ANOVA results of output characteristics of a V-grooved absorber plate

\begin{tabular}{|c|c|c|c|c|c|c|c|c|c|c|c|c|c|}
\hline \multirow[t]{2}{*}{ Source } & \multirow[t]{2}{*}{ DF } & \multicolumn{4}{|c|}{ Heat output } & \multicolumn{4}{|c|}{ Thermal resistance } & \multicolumn{4}{|c|}{ Overall thermal efficiency } \\
\hline & & Adj SS & Adj MS & $F$ value & $p$ value & Adj SS & Adj MS & $F$ value & $p$ value & Adj SS & Adj MS & $F$ value & $P$ value \\
\hline Model & 6 & $23,948.4$ & 3421.2 & 36.28 & 0.000 & 0.025560 & 0.003651 & 38.44 & 0.000 & 142.411 & 20.344 & 3.72 & 0.011 \\
\hline Linear & 3 & $23,573.2$ & 7857.7 & 83.33 & 0.000 & 0.025082 & 0.008361 & 88.01 & 0.000 & 132.546 & 44.182 & 8.07 & 0.001 \\
\hline$A$ & 1 & $20,995.4$ & $20,995.4$ & 222.66 & 0.000 & 0.025003 & 0.025003 & 263.18 & 0.000 & 2.985 & 2.985 & 0.55 & 0.469 \\
\hline$B$ & 1 & 514.3 & 514.3 & 5.45 & 0.031 & 0.000011 & 0.000011 & 0.11 & 0.741 & 22.418 & 22.418 & 4.10 & 0.057 \\
\hline$C$ & 1 & 2063.5 & 2063.5 & 21.88 & 0.000 & 0.000068 & 0.000068 & 0.72 & 0.407 & 107.143 & 107.143 & 19.58 & 0.000 \\
\hline Square & 1 & 26.8 & 26.8 & 0.28 & 0.600 & 0.000003 & 0.000003 & 0.04 & 0.852 & 0.298 & 0.298 & 0.05 & 0.818 \\
\hline$C^{*} C$ & 1 & 26.8 & 26.8 & 0.28 & 0.600 & 0.000003 & 0.000003 & 0.04 & 0.852 & 0.298 & 0.298 & 0.05 & 0.818 \\
\hline 2-Way interaction & 3 & 348.4 & 116.1 & 1.23 & 0.326 & 0.000475 & 0.000158 & 1.67 & 0.208 & 9.566 & 3.189 & 0.58 & 0.634 \\
\hline$A^{*} B$ & 1 & 347.3 & 347.3 & 3.68 & 0.070 & 0.000064 & 0.000064 & 0.67 & 0.422 & 5.039 & 5.039 & 0.92 & 0.349 \\
\hline$A^{*} C$ & 1 & 1.1 & 1.1 & 0.01 & 0.917 & 0.000411 & 0.000411 & 4.32 & 0.051 & 4.528 & 4.528 & 0.83 & 0.374 \\
\hline$B^{*} C$ & 1 & 0.0 & 0.0 & 0.00 & 1.000 & 0.000000 & 0.000000 & 0.00 & 0.958 & 0.000 & 0.000 & 0.00 & 1.000 \\
\hline Error & 20 & 1791.5 & 94.3 & & & 0.001805 & 0.000095 & & & 103.960 & 5.472 & & \\
\hline Total & 26 & $25,739.9$ & & & & 0.027365 & & & & 246.370 & & & \\
\hline
\end{tabular}

$R^{2}=96.01 \%$

$R^{2}$ (adjusted) $=93 \%$

$R^{2}($ predicted $)=91 \%$

\section{Flat absorber plate}

$$
\begin{aligned}
\mathrm{HO}= & 278.8+0.0460 A-0.104 B-4.570 C \\
& +0.01709 C * C-0.000200 A * B+0.000141 A \\
& * C+0.00327 B * C
\end{aligned}
$$

$$
\begin{aligned}
\mathrm{TR}= & 0.63113+0.000043 A-0.003020 B-0.008410 C \\
& +0.000026 C * C+0.000000 A * B-0.000000 A \\
& * C+0.000027 B * C \\
\mathrm{TE}= & 41.93+0.01211 A+0.0540 B-0.6400 C \\
& +0.002934 C * C-0.000037 A * B-0.000052 A \\
& * C+0.000093 B * C .
\end{aligned}
$$


Table 5 ANOVA results of output characteristics of a V-trough absorber plate

\begin{tabular}{|c|c|c|c|c|c|c|c|c|c|c|c|c|c|}
\hline \multirow[t]{2}{*}{ Source } & \multirow[t]{2}{*}{ DF } & \multicolumn{4}{|c|}{ Heat output } & \multicolumn{4}{|c|}{ Thermal resistance } & \multicolumn{4}{|c|}{ Overall thermal efficiency } \\
\hline & & Adj SS & Adj MS & $F$ value & $p$ value & Adj SS & Adj MS & $F$ value & $p$ value & Adj SS & Adj MS & $F$ value & $p$ value \\
\hline Model & 7 & $11,729.7$ & 1675.7 & 44.54 & 0.000 & 0.008606 & 0.001229 & 72.31 & 0.000 & 56.7934 & 8.1133 & 64.71 & 0.000 \\
\hline Linear & 3 & $11,383.4$ & 3794.5 & 100.86 & 0.000 & 0.008053 & 0.002684 & 157.88 & 0.000 & 52.8763 & 17.6254 & 140.57 & 0.000 \\
\hline$A$ & 1 & $10,736.8$ & $10,736.8$ & 285.39 & 0.000 & 0.006723 & 0.006723 & 395.45 & 0.000 & 34.3621 & 34.3621 & 274.06 & 0.000 \\
\hline B & 1 & 34.5 & 34.5 & 0.92 & 0.350 & 0.001205 & 0.001205 & 70.90 & 0.000 & 0.0108 & 0.0108 & 0.09 & 0.773 \\
\hline C & 1 & 612.0 & 612.0 & 16.27 & 0.001 & 0.000124 & 0.000124 & 7.30 & 0.014 & 18.5035 & 18.5035 & 147.58 & 0.000 \\
\hline Square & 1 & 295.4 & 295.4 & 7.85 & 0.011 & 0.000072 & 0.000072 & 4.24 & 0.053 & 3.0960 & 3.0960 & 24.69 & 0.000 \\
\hline$C^{*} C$ & 1 & 295.4 & 295.4 & 7.85 & 0.011 & 0.000072 & 0.000072 & 4.24 & 0.053 & 3.0960 & 3.0960 & 24.69 & 0.000 \\
\hline 2-Way interaction & 3 & 50.9 & 17.0 & 0.45 & 0.720 & 0.000481 & 0.000160 & 9.43 & 0.000 & 0.8211 & 0.2737 & 2.18 & 0.123 \\
\hline$A^{*} B$ & 1 & 25.0 & 25.0 & 0.67 & 0.425 & 0.000038 & 0.000038 & 2.26 & 0.150 & 0.0631 & 0.0631 & 0.50 & 0.487 \\
\hline$A^{*} C$ & 1 & 15.7 & 15.7 & 0.42 & 0.527 & 0.000000 & 0.000000 & 0.00 & 1.000 & 0.2700 & 0.2700 & 2.15 & 0.159 \\
\hline$B^{*} C$ & 1 & 10.2 & 10.2 & 0.27 & 0.608 & 0.000443 & 0.000443 & 26.05 & 0.000 & 0.4880 & 0.4880 & 3.89 & 0.063 \\
\hline Error & 19 & 714.8 & 37.6 & & & 0.000323 & 0.000017 & & & 2.3823 & 0.1254 & & \\
\hline Total & 26 & $12,444.5$ & & & & 0.008929 & & & & 59.1757 & & & \\
\hline
\end{tabular}

$R^{2}=99.04 \%$

$R^{2}$ (adjusted) $=99.18 \%$

$R^{2}$ (predicted) $=98.99 \%$

\section{V-groove absorber plate}

$$
\begin{aligned}
\mathrm{HO}= & -280+0.1177 A+0.88 B+3.32 C-0.0094 C * C \\
& -0.000797 A * B-0.000044 A * C-0.0000 B * C \\
\mathrm{TR}= & 0.006-0.000019 A+0.00039 B-0.00034 C \\
& -0.000003 C * C-0.000000 A * B+0.000001 \\
& A * C+0.000001 B * C \\
\mathrm{TE}= & -25.8+0.0157 A+0.074 B+0.57 C-0.00099 \\
& C * C-0.000096 A * B-0.000091 A * C \\
& -0.00000 B * C .
\end{aligned}
$$

\section{V-trough absorber plate}

$$
\begin{aligned}
\mathrm{HO}= & 575+0.0218 A-0.98 B-8.48 C+0.0312 C * C \\
& +0.000214 A * B+0.000169 A * C+0.00410 B * C \\
\mathrm{TR}= & 0.421+0.000055 A-0.002689 B-0.00555 C \\
& +0.000015 C * C-0.000000 A * B+0.000000 A \\
& * C+0.000027 B * C \\
\mathrm{TE}= & 59.6+0.00655 A-0.1027 B-0.800 C \\
& +0.003193 C * C-0.000011 A * B-0.000022 A * C \\
& +0.000896 B * C .
\end{aligned}
$$

\section{Effect of factors on $\mathrm{HO}$}

The significant model terms are $A, C, B$ in the flat absorber plate, $A, C, B, \mathrm{BC}$ in the $\mathrm{V}$-grooved absorber plate, and $A, C$ in the $\mathrm{V}$-trough absorber plate. They are also indicated by the Pareto chart, as shown in Figs. 2a, 3a, 4a.

The output surface diagrams demonstrating the interactive effect of $A, B$, and $C$ of the semi-circular HP for the maximum $\mathrm{HO}$ of three absorber plates show that by increasing the $A$, a gradual and a steep rise of the $\mathrm{HO}$ occur are shown in Fig. $(5 \mathrm{a}-\mathrm{c})$. The combined effect of the three parameters results in a decrease of the $\mathrm{HO}$. The maximum $\mathrm{HO}$ is achieved at $30^{\circ}$ and beyond $30^{\circ}$ decreased. The $\mathrm{HO}$ is affected mainly because of an HP's inclination and heat inlet at the vaporizing region (Nookaraju et al. 2018).

The heat transfer from the $\mathrm{V}$-groove absorber profile to HP is high compared to the flat absorber profile. The $\mathrm{V}$-groove profile has a high solar radiance that enhances thermal performance. The $\mathrm{HO}$ is affected mainly because of inclination (Hussein et al. 2006; Nookaraju et al. 2018; Holley and Faghri 2005).

The V-trough absorber profile has an increased solar concentration ratio of the absorber plate of up to two suns (Chun et al. 1999). This is because the heat transfer from the V-trough absorber profile to HP is high compared to other absorber plates' profiles. The heat transfer from the V-trough absorber profile to HP is limited. The $\mathrm{HO}$ of the HP decreases by increasing the heat inlet 


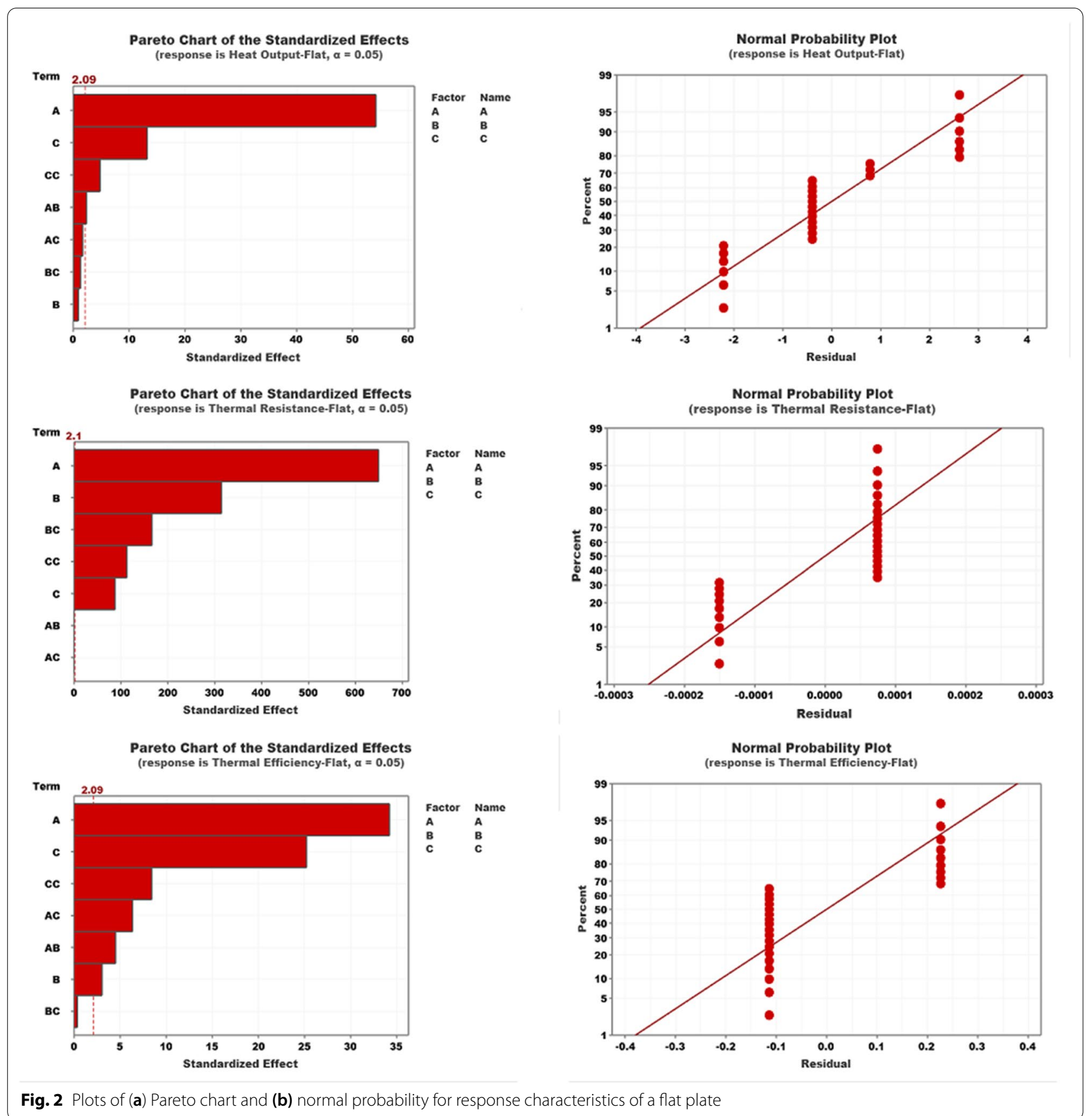

and inclination angle. $\mathrm{HO}$ is at a maximum of up to $50^{\circ}$ inclination and then falls. Hence, the influential input parameters are $A$ (heat inlet) at the vaporizing region and $B$ (mounting orientation).

\section{Effect of factors on TR}

Parameters $A, B, C$, and $B \times C$ in three collectors, but $A$ is the most influential model term are indicated by Pareto chart (refer Figs. 2b, 3b, 4b). The surface plots for the
$A, B$, and $C$ of HP's interactive effect on thermal resistance show that the increasing value of $A$ and minimum $\mathrm{C}$ value notably decreases the thermal resistance (refer to Fig. 6a). The TR gradually increases with the increase of the inclination in the case of a flat collector.

The interaction level effect of $A$ and $B$ is the same as the individual effect of $A$ in the $\mathrm{V}$-groove profile, because it has a high solar radiation absorption area compared to the flat type (Deng et al. 2015) and 


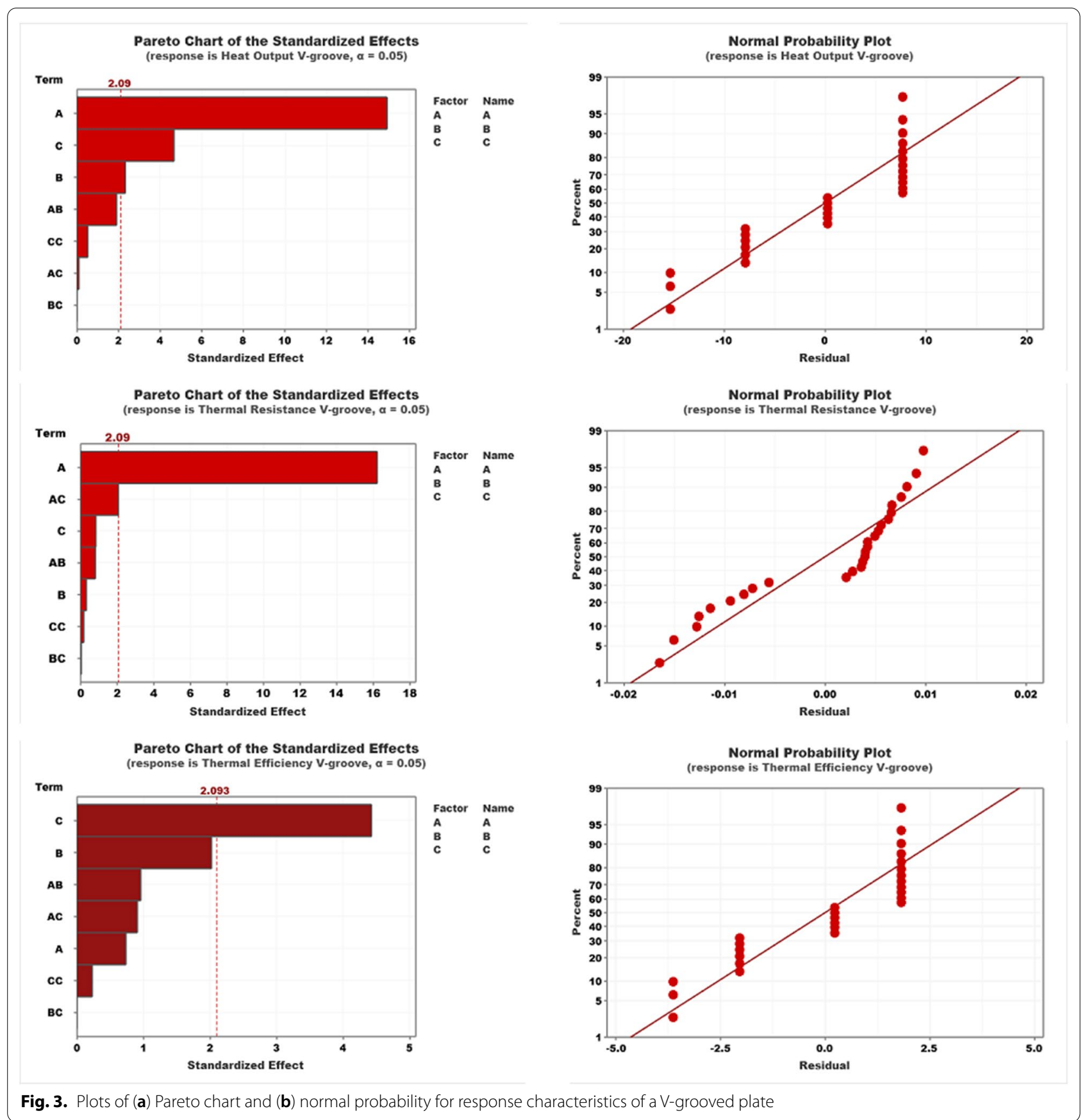

creates a pool boiling effect in the vaporizing region that enhance the TP. $A$ and C's interaction effect decreases thermal resistance with an increase of $A$ when $C$ attains maximum value in the condenser section initially (refer Fig. 6b). Later, the TR decreases with the rise of factor $C$. The interaction effect of factors $B$ and $C$ shows an increase in the TR initially and then shows sudden decreases compared to the individual influence of factor $B$ (Nookaraju et al. 2018).
The flow rate $(C)$ is alone adequate to produce a fluid film at the condensing side when it reaches the vaporizing region changes into fall over the film, which ultimately prevents any drying off inside the vaporizer. In V-grooved, the vapor of deionized water started to condense before reaching the condenser section, which resulted in maximum TR. The increase in heat input significantly decreases the thermal resistance at the 


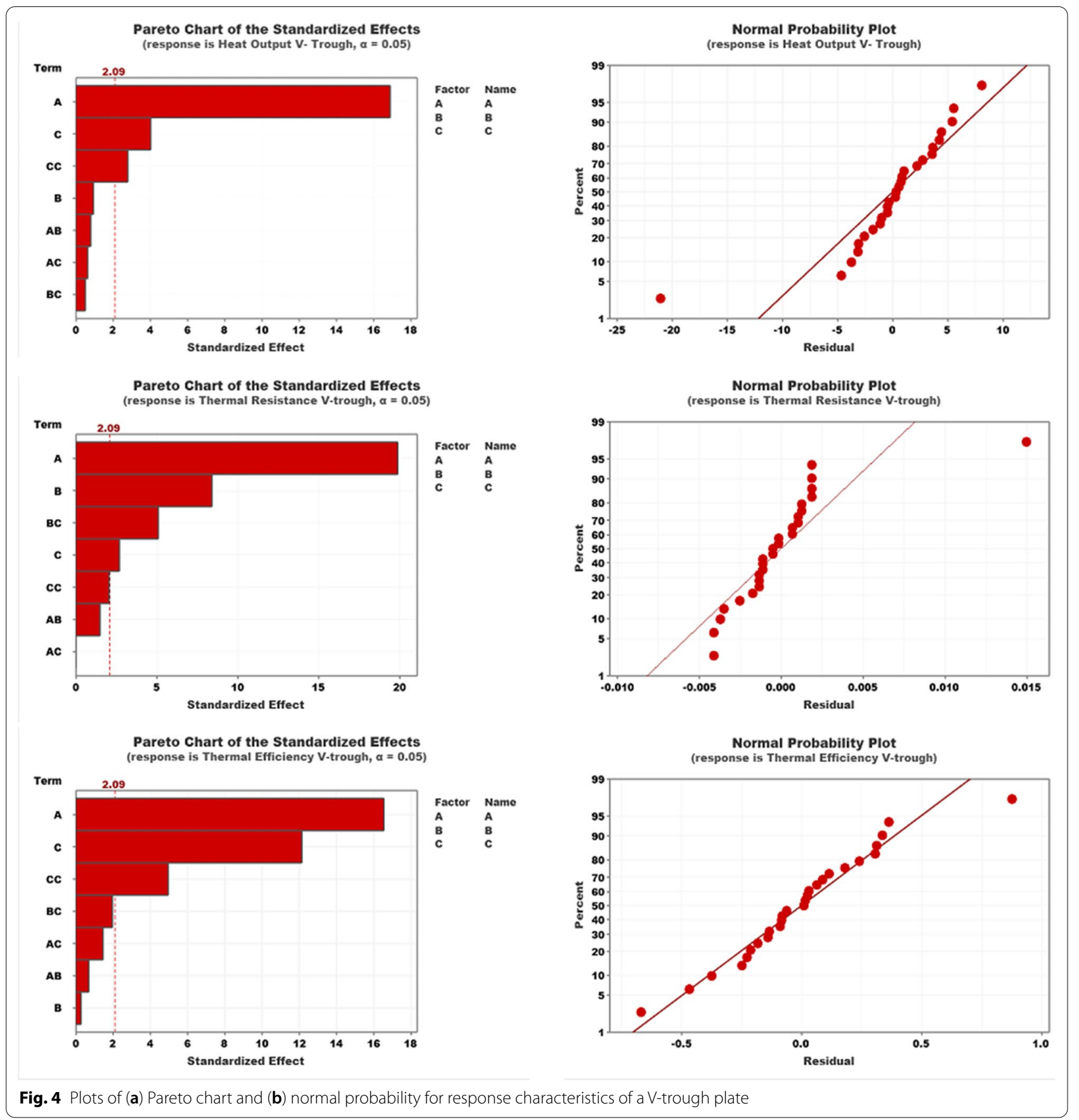

minimum inclination. The TR is initially low and, after that, increases with the rise of the inclination CHP.

The interactive effect of these factors is the same as the individual effect of heat input. In the V-trough system, TR is minimal at the minimum value of $B$. At a higher $C$ value, the vapor of the deionized water starts to condense before reaching the condenser section, which results in maximum thermal resistance. The TR is minimal at higher $A$ up to $50^{\circ}$ inclination. Here, the thermal resistance is associated with $\mathrm{C}$ in the condenser section and orientation (refer to Fig. 6c).

\section{Effect of factors on TE}

Factors $A, C, C \times C$ are found significant model terms in the case of flat and $\mathrm{V}$-trough collectors along with interaction level $A \times C$ and $A \times B$, but $C$ is found the most influential model terms in all the three verified with 
$\mathbf{a}$

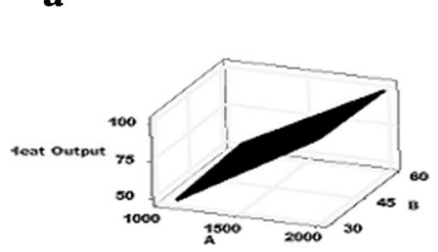

Surface Plots of Heat Output of Flat

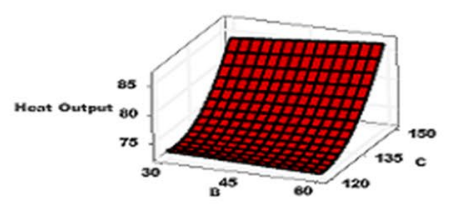

b
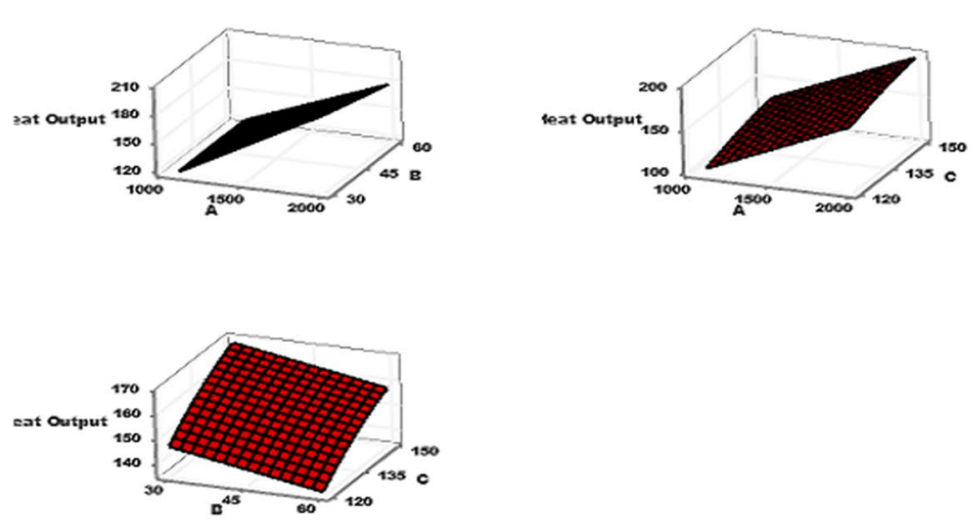

c

Surface Plots of Heat Output of $\mathrm{V}$ - Trough
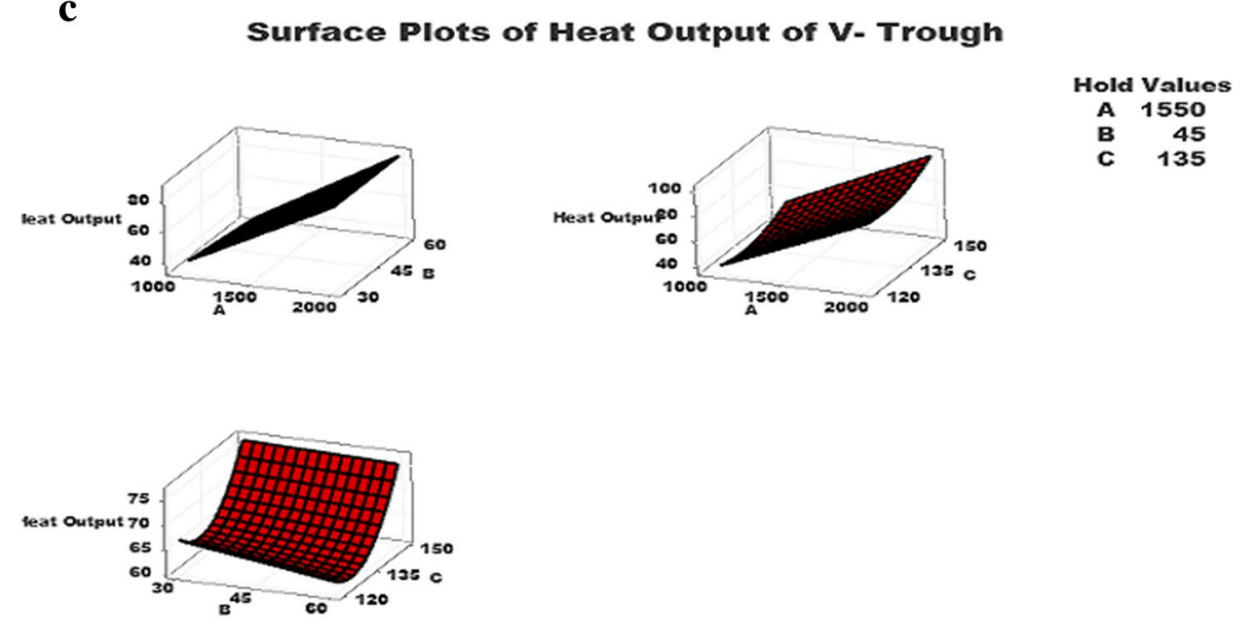

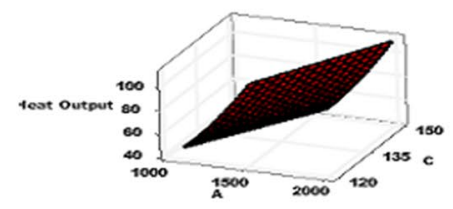

Hold

Values

A 1550

$\begin{array}{lr}\text { B } & 45 \\ \text { C } & 135\end{array}$

Fig. 5 3-D surface diagram of heat output for (a) flat, (b) V-grooved, (c) V-trough absorber plates 
Surface Plots of Thermal Resistance-Flat

$\mathbf{a}$
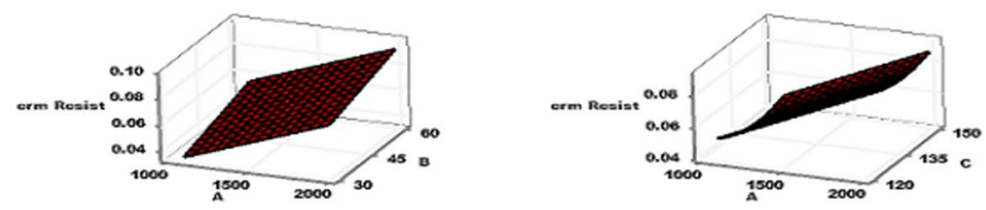

Hold Values

A 1550

$\begin{array}{lr}\text { B } & 45 \\ \text { C } & 135\end{array}$

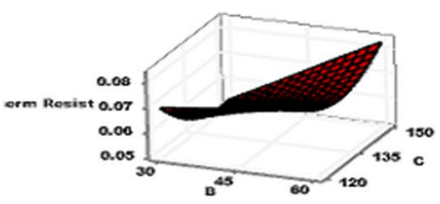

b

Surface Plots of Thermal Resistance of V-groove
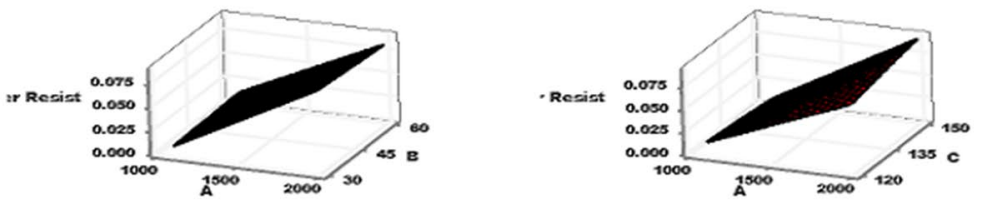

Hold Values

A 1550

$\begin{array}{lr}\text { B } & 45 \\ \text { C } & 135\end{array}$

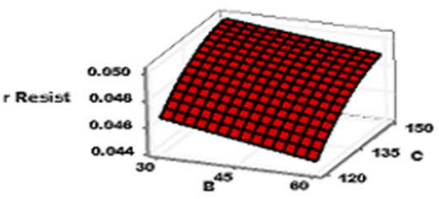

c

Surface Plots of Thermal Resistance of V-trough
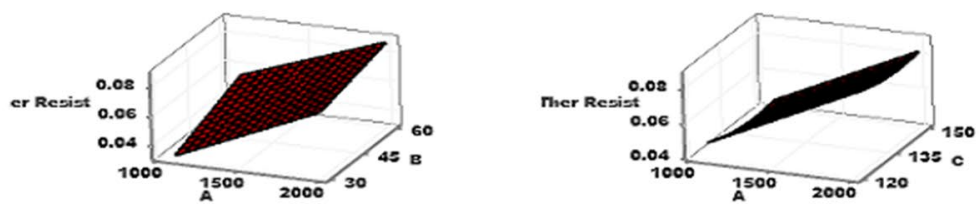

d Values

A 1550

$\begin{array}{lr}\text { B } & 45 \\ \text { C } & 135\end{array}$

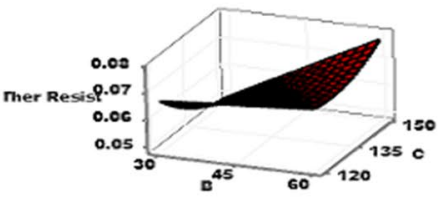

Fig. 6. 3-D surface diagram of thermal resistance for (a) flat, (b) $V$-grooved, (c) $V$-trough absorber plates 


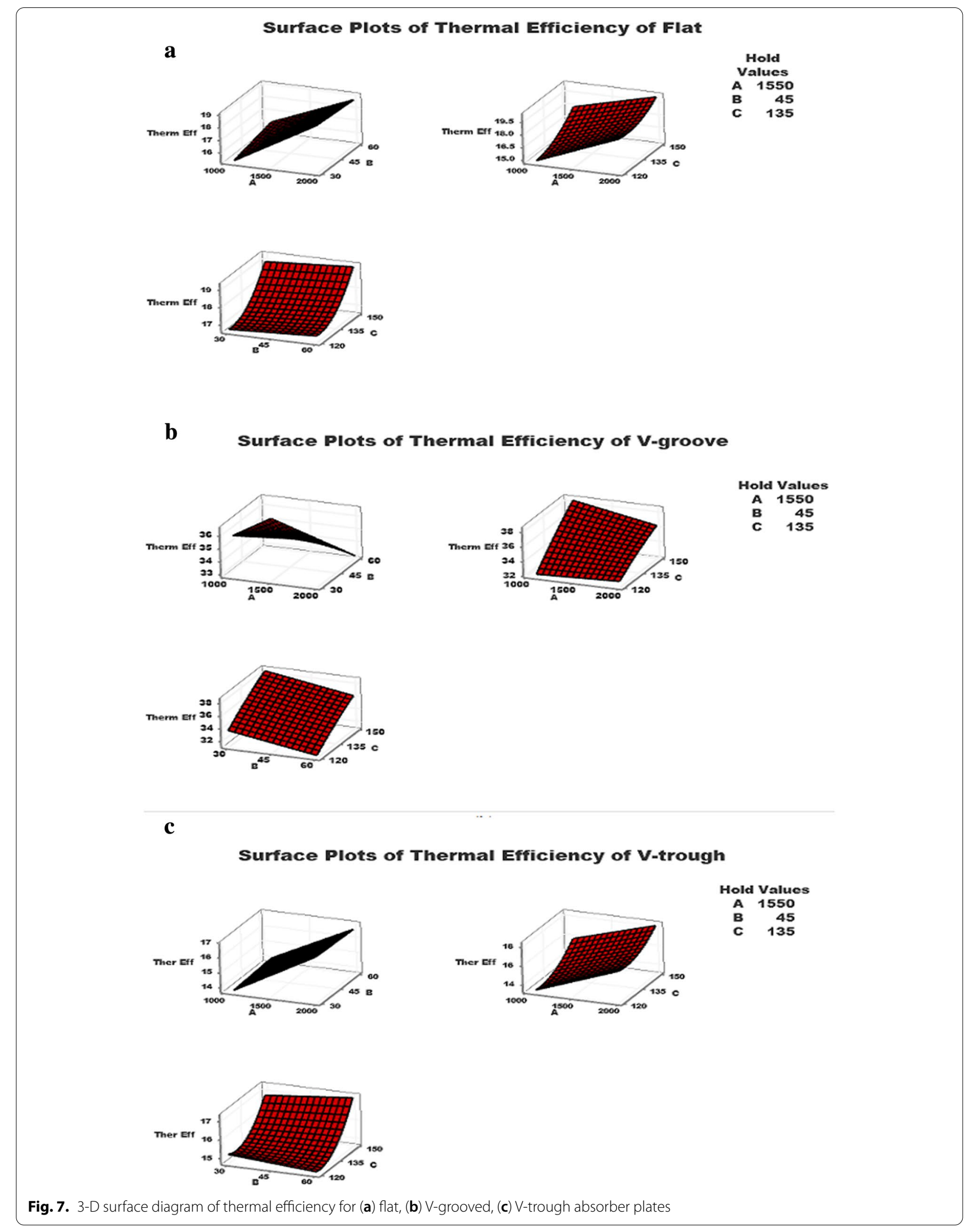


Table 6 Limits and targets for responses

\begin{tabular}{lllrl}
\hline Thermal performance & Aim & Low & Target & Up \\
\hline TE of V-trough & Maximum & 14.460 & 20.523 & \\
TR of V-trough & Maximum & & 0.030 & 0.09710 \\
HO of V-Trough & Maximum & 47.363 & 114.124 & \\
TE of V-groove & Maximum & 28.881 & 40.686 & \\
TR of V-groove & Maximum & & 0.098 & 0.02474 \\
HO of V-groove & Maximum & 107.378 & 215.270 & \\
TE of flat & Maximum & 14.460 & 20.523 & \\
TR of flat & Maximum & & 0.033 & 0.10250 \\
HO of flat & Maximum & 47.363 & 114.124 & \\
\hline
\end{tabular}

Pareto chart (refer Figs. 2c, 3c, 4c). 3-D surface plots involving the three parameters' interaction effect are shown in Fig. $7 \mathrm{a}-\mathrm{c}$. The TE of the HP is computed by the proportion of heat rejected at the condensing region to heat inlet at the vaporizing region (Zhang 2018). The effect of $A, B$, and $C$ on TE showed a gradual decrease with the increase of $A$ initially and then increases with increasing $C$ producing a sudden overall increase in TE. The interaction effect of the rise of $C$ and $B$ decreases the $\mathrm{TE}$. The temperature difference between the vaporizing and condensing region increases as the heat input level increases, contributing to increasing TE of HP.

The heat produced on the wall surface increases with high heat input starts converting water into vapor and rushing inside the condenser, in turn, increase TE. Hence, the influential input parameters are the heat input at the evaporator inclination as previously found by (Richter and Gottschlich 1994) and flow rate. TE decreases when the flow rate is minimum, and when the inclination angle increases beyond $50^{\circ}$ (Faghri 1995).

\section{Optimal results of parameters and responses using RSM optimization}

The optimized process parameters are used to determine the responses experimentally and compare them (refer to Tables 6, 7). From, Table 8 the semi-circular cross section (SC) HP performed better in the V-groove profile compared to the flat and V-trough profile. This is because $\mathrm{V}$-groove's angle ensures that the radiance is uniform throughout a semi-circular cross section because of the flat top surface and a semi-circular bottom surface. On the other hand, due to its shape, the flat plate is not capable of providing enough radiance. The $\mathrm{V}$-groove absorber profile enhanced the heat transfer phenomenon in the HP at an inclination of $30^{\circ}$ because of its enhanced absorptivity. Heat output at the condenser section increases when the heat inlet is raised (on the evaporator side). With the V-groove profile, heat output is found to be 214.30 Watts. Thermal resistance reduces quickly to a 0.04841 (minimum value) if heat input is raised. A low TR is attained at $30^{\circ}$ inclination (lower inclination). A semi-circular cross section in the V-groove profile has the highest thermal efficiency of $54.23 \%$ compared to

Table 7 Confirmation of experiment results

\begin{tabular}{lllll}
\hline Thermal performance & Optimal & Standard error fitness & 95\% confidence interval & 95\% PI \\
\hline TE of -trough & 17.23 & 0.25 & $(16.45,17.56)$ & $(16.25,18.310)$ \\
TR of -trough & 0.05618 & 0.00416 & $(0.0435,0.0565)$ & $(0.04211,0.0614)$ \\
HO of -Trough & 89.43 & 2.92 & $(83.56,94.24)$ & $(81.35,95.56)$ \\
TE of -groove & 38.20 & 1.54 & $(34.99,41.41)$ & $(32.46,43.94)$ \\
TR of -groove & 0.097780 & 0.000235 & $(0.098270,0.097290)$ & $(0.098657,0.096903)$ \\
HO of V-groove & 208.30 & 6.42 & $(194.90,221.69)$ & $(184.31,232.28)$ \\
TE of flat & 20.167 & 0.274 & $(19.595,20.738)$ & $(19.144,21.190)$ \\
TR of flat & 0.06957 & 0.00216 & $(0.06507,0.07408)$ & $(0.06151,0.07764)$ \\
HO of flat & 110.43 & 1.92 & $(106.43,114.44)$ & $(103.26,117.61)$ \\
\hline
\end{tabular}

Table 8 Optimal results for parameters and responses

\begin{tabular}{|c|c|c|c|c|c|c|c|c|c|c|c|c|c|}
\hline \multirow[b]{2}{*}{ Solution } & \multicolumn{3}{|c|}{$\begin{array}{l}\text { Input } \\
\text { parameters }\end{array}$} & \multicolumn{3}{|c|}{ Flat absorption plate } & \multicolumn{3}{|c|}{$\begin{array}{l}\text { V-grooved absorption } \\
\text { plate }\end{array}$} & \multicolumn{4}{|c|}{ V-trough absorption plate } \\
\hline & A & B & $\mathrm{C}$ & $\mathrm{HO}$ & TR & $\mathrm{TE}$ & HO & TR & $\mathrm{TE}$ & $\mathrm{HO}$ & TR & TE & Composite desirability \\
\hline 1 & 2000 & 30 & 150 & 110.43 & 0.069575 & 20.1669 & 208.295 & 0.09778 & 38.2012 & 110.434 & 0.064175 & 20.1669 & 0.800782 \\
\hline
\end{tabular}




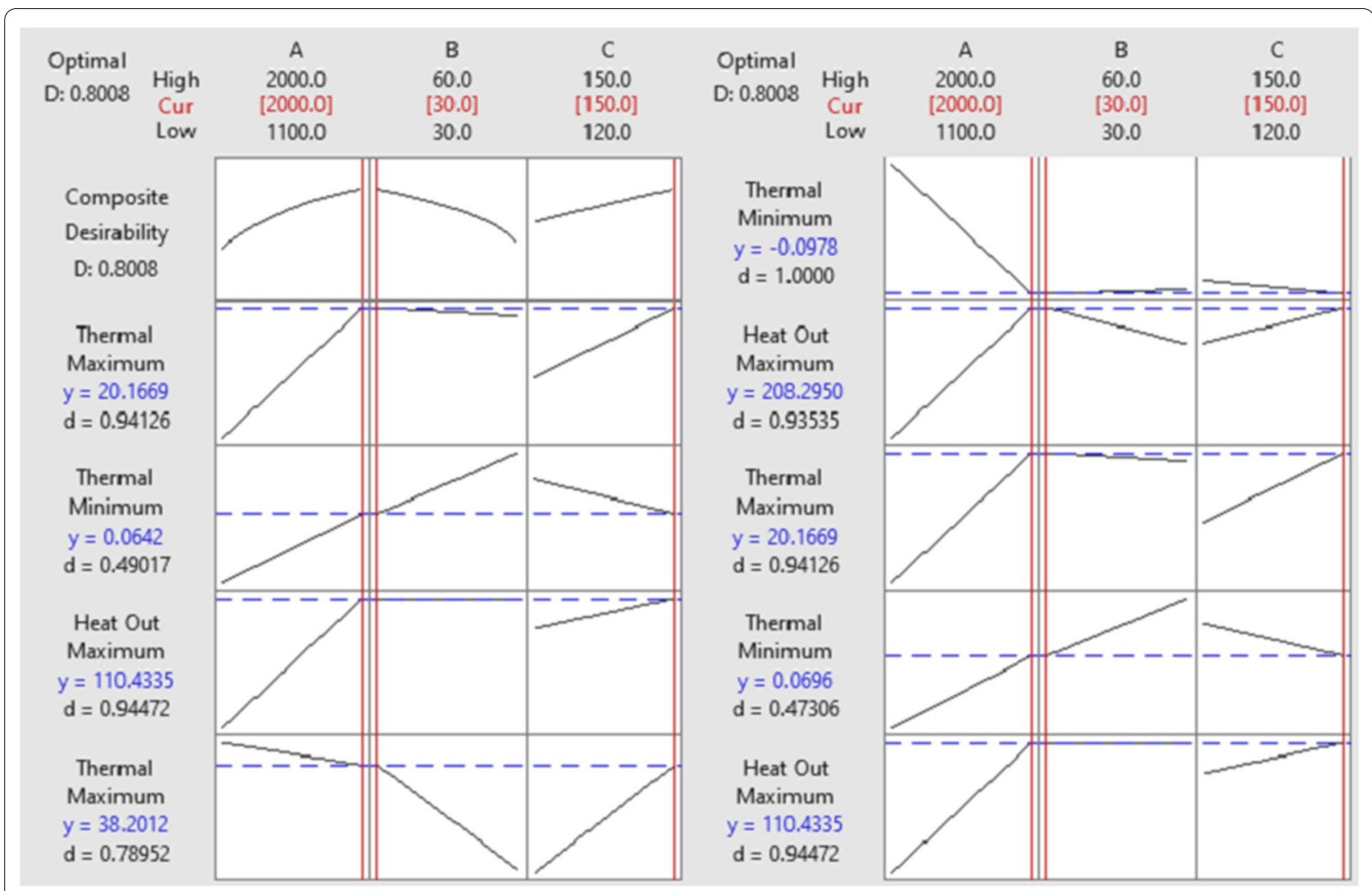

Fig. 8 Result of composite desirability

other absorber plate profiles. This is due to the V-groove absorber profile, which has high solar radiation absorption compared to a flat profile (Nookaraju et al. 2018). The V-groove increases the surface area, paving the way for high heat absorption and creates a pool boiling effect in the evaporator region that enriched the TP of SCHP.

The liquid drops struck into a vapor of condenser, because their higher paces are signified as the trapped limit. Further increased deposition of water in the condenser would result in dry status in the evaporator. Thus, wall temperatures will increase in the evaporator portion above $30^{\circ}$ inclination. Trapped limit and dry state decrease TP of the SCHP in flat and V-groove absorber profiles. In a semi-circular cross section HP, the VGAP profile performs $15 \%$ better than the FAP profile and $25 \%$ better than the VTAP profile. Further to the absorber profiles, V-trough and V-groove have increased the concentration ratio of solar radiance to twice that of a flat profile (Deng et al. 2015). Various responses at optimal values of input using composite desirability are shown in Fig. 8.

\section{Conclusion}

In this work, a semi-circular cross section of the HP and three absorber plates' profiles are investigated experimentally. The optimized values for the input parameters carried out by the RSM using CCD design are:

- Flat: $A$ of $2000 \mathrm{~W} ; B$ of $30^{\circ}$; $C$ of $135 \mathrm{ml} / \mathrm{min}$.

- V-grooved: $A$ of $2000 \mathrm{~W} ; B$ of $30^{\circ} ; C$ of $150 \mathrm{ml} / \mathrm{min}$.

- V-trough: $A$ of $2000 \mathrm{~W} ; B$ of $30^{\circ} ; C$ of $135 \mathrm{ml} / \mathrm{min}$.

The best performing absorber plate profile is VGAP. The heat output obtained is $240.3 \mathrm{~W}$, thermal resistance $0.0484{ }^{\circ} \mathrm{C} / \mathrm{W}$, and thermal efficiency of $54.23 \%$. This is due to the semi-circular cross section contributing to the proper execution of the vaporization and condensation cycle as well as aids the flow of condensate from the region of condenser towards the evaporator. Furthermore, the V-groove geometry of the absorber plate enhances the incidence of radiance onto the semi-circular HP due to the angle of the V-groove, making sure that the radiance is uniform throughout on a semi-circular 
cross section because of the flat top surface and a semicircular bottom surface. The flat-plate on the other hand, due to its shape, is not capable of providing enough radiance. Though the radiance is maximum for the $\mathrm{V}$-trough at a particular orientation angle, the radiance is not uniformly transferred to the SCHP, resulting in performance lower than that of the V-groove profile. Furthermore, $\mathrm{V}$-trough and V-groove's absorber profiles have increased the concentration ratio of solar radiance to twice that of a flat profile. The validation by experimentation and RSM found in good agreement.

An increase of heat input forces improved heat transmission to increase the $\mathrm{HO}$ by dropping $\mathrm{TR}$, which consequently increases TE. The highest $\mathrm{HO}$ is attained at a $30^{\circ}$ mounting angle, because TR is the least with higher TE. The flowing water rate is seen to be maximizing TE by lowering TR. Highest $\mathrm{HO}$ is attained at $150 \mathrm{ml} / \mathrm{min}$ (maximum flow rate) due to the quicker heat transmission rate. The accuracy of predicted models can be combined with the genetic algorithm, swarm optimization to improve the existing models.

\begin{abstract}
Abbreviations
HP: Heat pipe; HPSC: Heat pipe solar collectors; CFD: Computational fluid dynamics; CCD: Central composite design; RSM: Response surface methodology; VGAP: V-Grooved absorber plate; SCHP: Semi-circular heat pipe; CHP: Circular heat pipe; CFCHE: Cross-flow condenser heat exchanger; VTAP: V-Trough absorber plate; R-Sq: $R^{2}$-Coefficient of determination; DF: Degree of freedom; Adj: Adjusted; Pred.: Predicted; MS: Mean squares; SS: Sum of squares.
\end{abstract}

\section{Acknowledgements}

Not applicable.

\section{Authors' contributions}

MY and MA conceived and designed the study. MY wrote the paper. MA reviewed and edited the manuscript. Both authors read and approved the final manuscript.

\section{Funding}

The authors received no financial support for the research and/or for the publication of this article.

\section{Availability of data and materials}

The data analyzed for this manuscript are part of our research work and are available for public use.

\section{Ethical approval and consent to participate}

This article does not contain any studies with human participants or animals performed by any of the authors.

\section{Competing interests}

The authors claim no competing interests.

Received: 14 November 2019 Accepted: 26 December 2020

Published online: 07 January 2021

\section{References}

Azad, E. (2008). Theoretical and experimental investigation of heat pipe solar collector. Experimental Thermal and Fluid Science, 32(8), 1666-1672.
Azad, E. (2012). Assessment of three types of heat pipe solar collectors. Renewable and Sustainable Energy Reviews, 16(5), 2833-2838.

Chun, W., Kang, Y. H., Kwak, H. Y., \& Lee, Y. S. (1999). An experimental study of the utilization of heat pipes for solar water heaters. Applied Thermal Engineering, 19(8), 807-817.

Deng, Y., Zhao, Y., Quan, Z., \& Zhu, T. (2015). Experimental study of the thermal performance for the novel flat plate solar water heater with micro heat pipe array absorber. Energy Procedia, 70, 41-48.

Facão, J., \& Oliveira, A. C. (2006). Analysis of a plate heat pipe solar collector. International Journal of Low Carbon Technologies, 1(1), 1.

Faghri, A. (1995). Heat pipe science, and technology. Kanpur: Global Digital Press.

Goshayeshi, H. R., Goodarzi, M., Safaei, M. R., \& Dahari, M. (2016). Experimental study on the effect of inclination angle on heat transfer enhancement of a ferrofluid in a closed loop oscillating heat pipe under magnetic field. Experimental Thermal and Fluid Science., 74, 265-270. https://doi. org/10.1016/j.expthermflusci.2016.01.003.

Goshayeshi, H. R., Safaei, M. R., Goodarzi, M., \& Dahari, M. (2016). Particle size and type effects on heat transfer enhancement of Ferro-nanofluids in a pulsating heat pipe. Powder Technology, 301, 1218-1226. https://doi. org/10.1016/j.powtec.2016.08.007

Holley, B., \& Faghri, A. (2005). Analysis of pulsating heat pipe with capillary wick and varying channel diameter. International Journal of Heat and Mass Transfer, 48(13), 2635-2651.

Hooman, K., Safaei, M. R., Togun, H., \& Dahari, M. (2019). Thermohydraulics of the liquid films in rotating heat pipes. International Journal of Numerical Methods for Heat and Fluid Flow, 30(6), 2861-2866. https://doi. org/10.1108/HFF-02-2019-0097.

Hull, J. (1986). Analysis of heat transfer factors for a heat pipe absorber array connected to a common manifold. Journal Sol Energy Eng., 108, 11-16.

Hussein, H. (2003). Optimization of a natural circulation two-phase closed thermosyphon flat plate solar water heater. Energy Conversion and Management, 44(14), 2341-2352.

Hussein, H., El-Ghetany, H., \& Nada, S. (2006). Performance of wickless heat pipe flat plate solar collectors having different pipes cross-sections geometries and filling ratios. Energy Conversion and Management, 47(11-12), 1539-1549.

Khalajzadeh, V., Heidarinejad, G., \& Srebric, J. (2011). Parameters optimization of a vertical ground heat exchanger based on response surface methodology. Energy and Buildings, 43(6), 1288-1294.

Nookaraju, B. C., Kurmarao, P., Nagasarada, S., Karthikeyan, R., \& Vinay, A. (2018). Optimization of process parameters of helical grooved heat pipe using response surface methodology. Materials Today: Proceedings, 5(2), 5262-5271.

Olia, H., Torabi, M., Bahiraei, M., Ahmadi, M. H., Goodarzi, M., \& Safaei, M. R. (2019). Application of nanofluids in thermal performance enhancement of parabolic trough solar collector: state-of-the-art. Applied Sciences., 9(3), 463. https://doi.org/10.3390/app9030463.

Ramakrishnan, R., \& Arumugam, R. (2011). Application of response surface methodology (RSM) for optimization of operating parameters and performance evaluation of cooling tower cold water temperature. An International Journal of Optimization and Control: Theories and Applications, 2(1), 39-50

Richter, R., \& Gottschlich, J. M. (1994). Thermodynamic aspects of heat pipe operation. Journal of Thermophysics and Heat transfer, 8(2), 334-340.

Riffat, S., \& Zhao, X. (2004). A novel hybrid heat pipe solar collector/CHP system-Part 1: system design and construction. Renewable Energy, 29(15), $2217-2233$.

Riffat, S., Zhao, X., \& Doherty, P. (2005). Developing a theoretical model to investigate thermal performance of a thin membrane heat-pipe solar collector. Applied Thermal Engineering, 25(5-6), 899-915.

Sarafraz, M. M., \& Safaei, M. R. (2019). Diurnal thermal evaluation of an evacuated tube solar collector (ETSC) charged with graphene nanoplateletsmethanol nano-suspension. Renew Energy, 142, 364-372. https://doi. org/10.1016/j.renene.2019.04.091.

Sarafraz, M., Tilii, I., Baseer, M., \& Safaei, M. (2019). Potential of solar collectors for clean thermal energy production in smart cities using nano-fluids: experimental assessment and efficiency improvement. Applied Sciences, 9(9), 1877. https://doi.org/10.3390/app9091877.

Sarafraz, M. M., Tilil, I., Tian, Z., Bakouri, M., \& Safaei, M. R. (2019). Smart optimization of a thermosyphon heat pipe for an evacuated tube solar collector 
using response surface methodology (RSM). Physica A: Statistical Mechanics and its Applications., 534, 122146. https://doi.org/10.1016/j.physa .2019 .122146

Saravanan, M., \& Karunakaran, N. (2014). Experimental analysis of heat pipe with V-trough solar collector. International Journal of Research in Advent Technology, 53, 13-17.

Senthilkumar, R., Prabhakaran, J., \& Karthikeyan, M. (2014). Analysis of energy conservation potential of the heat pipe using response surface methodology. An International Journal Development Research, 4(3), 570-574.

Wei, L., Yuan, D., Tang, D., \& Wu, B. (2013). A study on a flat-plate type of solar heat collector with an integrated heat pipe. Solar Energy, 97, 19-25.

Yunus, M., \& Alsoufi, M. S. (2016a). Multi-objective optimization of joint strength of dissimilar aluminum alloys formed by friction stir welding using taguchi-grey relation analysis. International Journal of Engineering and Technology IJET-IJENS, 16(04), 10-17.

Yunus, M., \& Alsoufi, M. S. (2016b). Multi-output optimization of tribological characteristics control factors of thermally sprayed industrial ceramic coatings using hybrid Taguchi-grey relation analysis. Friction, 4(3), 208-216.
Yunus, M., \& Alsoufi, M. (2018). Development of a heat pipe and grey based Taguchi method for multi-output optimization to improve thermal performance using hybrid nano-fluids. Frontiers in Heat and Mass Transfer, $12,1-8$.

Zhang T, Experimental study on a forced-circulation loop thermosiphon solar water heating system, International Journal of Photoenergy, 2018, 2018.

Zhang, X.-R., Zhang, Y., \& Chen, L. (2014). Experimental study on solar thermal conversion based on supercritical natural convection. Renewable Energy, 62, 610-618.

\section{Publisher's Note}

Springer Nature remains neutral with regard to jurisdictional claims in published maps and institutional affiliations.

\section{Submit your manuscript to a SpringerOpen ${ }^{\odot}$ journal and benefit from:}

- Convenient online submission

- Rigorous peer review

- Open access: articles freely available online

- High visibility within the field

- Retaining the copyright to your article

Submit your next manuscript at $\boldsymbol{\nabla}$ springeropen.com 